\title{
Anxiety and Depression: Different Sides of the Same Coin? An Examination of Trends in the Medicalization of Both Disorders in Belgium
}

Kilian Van Looy ( $\square$ kilian.vanlooy@uantwerpen.be)

University of Antwerp: Universiteit Antwerpen https://orcid.org/0000-0002-7407-6003

Sarah Van de Velde

University of Antwerp: Universiteit Antwerpen

\section{Research Article}

Keywords: Medicalization of mental health, depressive disorders, anxiety disorders, psychopharmacology, medical sociology

Posted Date: January 27th, 2022

DOI: https://doi.org/10.21203/rs.3.rs-1272615/v1

License: () (7) This work is licensed under a Creative Commons Attribution 4.0 International License. Read Full License 


\section{Abstract}

Background: While medicalization trends of feelings of anxiety and depression have been described in great detail, an empirical examination of these trends is to date lacking. The current study fills this gap in the literature by mapping shifts in type of medicine use for feelings of anxiety and depression, as well as by examining whether a social gradient mediated these suggested shifts.

Methods: We analyzed data from three repeated cross-sectional waves (2004, 2008, and 2013) of the Belgian National Health Interview Survey (HIS). Multinomial logistic regression were applied to estimate shifts in psychotropic drugs use over the observed period.

Results: Using an ideal-typical distinction between traditional anxiety drugs (psycholeptics) and depression drugs (psychoanaleptics), we found that treatment methods for feelings of anxiety and depression were converging. Persons having anxiety feelings consumed less psycholeptic drugs, in favor of psychoanaleptic drugs throughout the observed period. Moreover, these shifts were partially mediated by educational level. Persons with higher education consumed less psychotropic drugs than those with lower education, suggesting trends of demedicalization for feelings of anxiety and depression.

Conclusion: Our study shows that psycholeptics increasingly give way to psychoanaleptics in the treatment of both anxiety and depression, despite several scientists calling their effectiveness for both disorders into question.

\section{Background}

Anxiety and depression are the most prevalent mental disorders worldwide (1). Approximately one in five persons experience one of both disorders during their lifetime, and these numbers continuously increase over time $(2,3)$. There is ample research that focuses on either disorder, yet social scientists rarely examine their interrelatedness empirically $(4,5)$. This begs the question of whether anxiety disorder (AD) and depressive disorder (DD) are different sides of the same coin?

Indeed, in sociology, the similarity between $A D$ and DD is often emphasized, referring to their shared risk factors and social outcomes $(3,6)$. Social constructionists even claim that distinctions between mental disorders are a consequence of medicalization, which is defined as the process by which a nonmedical problem, behavior, or human condition is defined and/or treated as a medical problem (7). Mental disorders could indeed be framed as the "medicalization of deviance" (8), perhaps even as "transforming normality into pathology" (9). Yet, the way mental disorders like AD and DD are medicalized, changed drastically throughout the years, resulting in contrasting diagnoses and treatment methods (7). Consequently, this has led to very different outcomes for the numerous individuals that have been treated with either (or both) disorders and how society perceives these disorders and treatment methods (4, 10 , 11). Only, to our knowledge, no empirical research exists that scrutinizes how this process affected changes in treatment methods over time and how this differs between persons with feelings of anxiety versus feelings of depression.

Our research aims to address this gap by investigating how the medicalization of feelings of anxiety and depression evolved in recent years, specifically focusing on psychotropic drugs consumption. Traditionally, anxiety feelings have been treated with tranquilizing psychotropic drugs, such as benzodiazepines, which could broadly be classified under the term psycholeptics (12). On the other hand, feelings of depression are generally treated with stimulants such as selective serotonin reuptake inhibitors (SSRIs), classified as psychoanaleptics (13). In the current paper, we use this distinction as an idealtypical dichotomy, allowing us to gauge the foundations of the medicalization processes of both disorders.

In addition, we assess whether a social gradient might mediate these suggested shifts. This second aim is guided by the great body of literature that deals with inequalities in both the access to and use of mental healthcare (14). Our study will use education level as a proxy for this social gradient, as education is identified as one of the most fundamental causes of social disparities in healthcare use (15), with those who are higher educated generally taking on a more active role in the treatment process (16).

In doing so, we will make use of the second (2004), third (2008), and fourth (2013) waves of the Belgian nationally representative Health Interview Survey (HIS), executed via repeated cross-sections. This paper ascertains (i) whether shifts in treatment for feelings of anxiety and depression have occurred during the observed period while focusing on both types of psychotropic drugs use, (ii) whether these suggested shifts are comparable, and (iii) whether a social gradient might mediate these shifts

\section{The medicalization of feelings of anxiety and depression}

In the literature, anxiety disorder (AD) is generally defined as having an excessive reaction to a future threat (17). In turn, Depression disorder (DD) is defined as having an excessive manifestation of sadness (18). Nevertheless, "excessiveness" is not defined at all, leaving AD or DD diagnoses subject to individual interpretation, often in combination with diagnostic tools, such as elaborate symptom checklists (19). Importantly, moreover, is that these definitions and symptoms have changed dramatically throughout the last decades $(4,20)$, with striking shifts that align with the first and second generations of medicalization (7). This has had an undeniable impact on the way these disorders are perceived (by society, clinicians, or patients), and is directly linked to their diagnoses, prevalence, and treatment (19).

A quintessential example of this are the shifts in the definition of AD and DD by the American Psychological Association (APA), which had (and still has) an eminent influence on the medicalization of feelings of anxiety and depression in most high-income countries, including Belgium. Over the last decades, the APA systematically widened its sphere of influence by monopolizing mental disorders, deciding which feelings should be classified as disorders and which should not $(9,21)$. Over the years, the APA systematically increased the number of ADs, framing a growing number of personal characteristics as AD pathologies (e.g., shyness becoming social phobia) (22). In turn, while DD was still quite obscure before the 1980s (with only a few persons qualifying for its severe symptoms and diagnostic criteria), this changed with the publication of the third diagnostic and statistical manual (DSM-III): DD were increasingly 
becoming more generalized under the umbrella term of 'major depressive disorder' (MDD). For instance, the DSM-V discarded the contested 'bereavement clause', which excluded "normal" feelings of sadness from depression, induced by, for example, grieving a close death, thereby inevitably causing diagnoses (and consequently the use of psychoanaleptics, such as antidepressants) to rise significantly (23). In succession to AD, DD consequently became "psychiatry's most marketable diagnosis" (24).

These shifts in the delineation and definition of AD and DD went hand in hand with shifts in the prescription and consumption of psychotropic drugs. Stimulated by the rapid development of these drugs during the last century, the dominant idea grew to cure mental disorders with medications. Importantly, however, is these new treatment methods often merely suppressed symptoms, rather than eliminating their cause $(20,21)$. Even so, these methods were continuously promoted by professional organizations and the pharma industry, first to clinicians, and then to the public, giving rise to the age of psychotropics (24).

However, while developments in psychoanaleptic drugs treatment initially showed promise, psycholeptics were increasingly perceived dangerous due to their addictive properties $(25,26)$. As a result; in recent years, psychoanaleptics have become the go-to remedy for both feelings of anxiety and depression, and an increasingly wider array of other mental disorders as well $(25,26)$. Aggressively pushed forward by the APA, the use of psychoanaleptics has increased steadily for all ages, genders, and ethnic-racial groups $(25,26)$. There is an increasing overlap in how both AD and DD are treated, causing the conceptual lines between them to blur. Or, as Ehrenberg (27) notes: "Everything becomes depression, because antidepressants act on everything".

Within Belgium, where this study is situated, mental healthcare policy largely follows the APA's DSM recommendations for diagnoses and treatment options (see e.g. 28). As such, it is estimated that nearly one-tenth of the adult Belgian population used an antidepressant in the past thirty days (29). In turn, while still having a higher consumption rate in Belgium (29), the use of psycholeptics decreased or at least stabilized, especially for long-term use (30).

The aforementioned shifts in the medicalization of feelings of anxiety and depression happened in an area of the emergence of managed care systems. Elaborate insurance schemes typically characterize these systems, mixing both basic (public) plans with more privatized "extra" plans for those who can afford it (31). At best, basic security is offered to those most in need (as is the case in Belgium, see e.g. 32), yet in more privatized national healthcare systems, such as the USA, this is less evident (33). Industrialized healthcare systems are, however, hypothesized to converge to one another, i.e. leading privatized systems to become more centralized and vice versa (e.g. 34). The same is true for Belgium. What types of treatment are refundable is constantly evaluated by government subsidiaries, such as the National Institute for Health and Disability Insurance (NIHDI). For example, in 2013, the Belgian Psychotropics Experts Platform (BelPEP) was founded as a result of a worrisome publication concerning the (over) use of psychotropic drugs within the Belgian population (35). BelPEP (35) advised the NIHDI to restrict the use of these kinds of psychotropic drugs, particularly psycholeptics. This led to the formal Royal Resolution of September 6, 2017, significantly tightening prescription regulation, e.g., to individuals with a history of addiction.

\section{The social gradient within medicalization}

Added to the already present social gradient within the prevalence of disorders such as AD and DD, inequalities also exist in the medicalization of both disorders, highlighting its complexity and diversity (e.g. 36). During the first generation of medicalization, these inequalities were largely (re)produced by clinicians, for instance, by choosing who they ultimately prescribe certain medications or treatments to (37). Moreover, it is argued that at least some prevalence disparities, such as individuals with a more precarious socioeconomic position being more likely to have feelings of anxiety and depression (see e.g. 38), are partially mediated by this process, whereas individuals with higher SES might simply enjoy better healthcare on average (14,39).

The nature of this stratification changed during the second generation of medicalization. With healthcare becoming more an individual responsibility, patients became more active in their personal healthcare management. In the previous century, treatment with psycholeptic drugs was highly promoted to the middle and upper classes, leaving the lower classes to miss out $(4,7)$. However, when the perception towards these medications shifted and the upper class abandoned them, they only just started to become available for the lower classes, leaving them to become their new primary users (4).

Educational level seems of particular importance in this context. While persons with lower educational level are generally more at risk of anxiety feelings (40) and depressive feelings (41), it also influences health care behavior in patients. Persons with a higher educational level are generally less likely to consume psychotropic drugs $(42)$ and take on a more active role as a patient $(7,16)$. Furthermore, they tend to be more informed concerning different treatment options, which helps them gain access to newer forms of treatment (16). Persons with lower education are, however, more likely to consume psycholeptics such as benzodiazepines (42). Additionally, persons with higher education increasingly opt for alternative medicine, with a great emphasis on preventative health behavior (43). This suggests there is an ongoing trend of demedicalization and shifts in help-seeking behavior, especially in those that are higher educated $(16,43)$.

\section{Hypotheses}

The aim of this study is to describe how the medicalization of feelings of anxiety and depression may have shifted throughout the observed period. Based on the literature, we expect that a shift from psycholeptic to psychoanaleptic drugs will have occurred (hypothesis 1), and that this shift was most outspoken for persons having more anxiety feelings with them being less likely to consume psycholeptic drugs, in favor of psychoanaleptic drugs (hypothesis 2 ). Lastly, we expect that persons with a higher educational level will be less likely to consume either type of psychotropic drugs compared to those with lower education (hypothesis 3). This would fit in with current demedicalization trends, where we expect a general downward trend in either type of psychotropic drugs consumption to be highest in those with higher educational levels (hypothesis $3 b$ ).

\section{Methods}

\section{Data}


This study used data from the third (2004), fourth (2008), and fifth (2013) waves of the Belgian Health Interview Survey (HIS), executed by Sciensano, and commissioned by the Belgian Federal Government. This data was accessible upon request to the Privacy Commission. Extensive documentation and further protocols could be found on the provider's website (his.wiv-isp.be). Using nationally representative samples via a stratified, multistage, clustered design, the HIS administered standardized questionnaires through face-to-face interviews, both written and orally, on the household level and the individual level. From each household, up to four persons were selected for the individual interview, though this study selected only the primary individual to provide for independent measures, as is required for regression analyses. Moreover, we only included persons aged between 18 and 75 in our analyses. While the HIS was also executed in 1998, 2001, and 2018, we excluded these waves since they do not provide consistent measures for our used variables. The final sample comprised of 7214 respondents.

\section{Variables}

Type of psychotropic drugs used - Making use of the Anatomical Therapeutic Chemical classification (ATC), which is recommended by the World Health Organization (44) as an international standard for drug utilization studies, respondents' psychotropic drugs use was assessed. This resulted in a categorical variable, measuring specifically the use of psycholeptic (ATC code N05) and psychoanaleptic (ATC code N06) medication. The variable consisted of four categories: use of (1) neither medications, (2) only psycholeptic, (3) only psychoanaleptic drugs, or (4) use of both medications simultaneously.

Wave - The three waves of data collection $(2004,2008$, and 2013$)$ were used as indicators of time-periods. 2008 was taken as the reference period.

Anxiety feelings were measured through a ten-item scale within the Symptom Checklist Revised (SCL-90-R) scale (45). Respondents were asked to indicate how often they have certain feelings or expressed specific behaviors (feeling fearful, heart pounding, nervousness, trembling, suddenly scared for no reason, feeling tense, spells of terror or panic, feeling so restless you could not sit still, feeling something bad is going to happen or thoughts and images of a frightening nature). Response categories ranged between 1 (not at all) and 5 (extremely). The scale total was the sum of all item-responses, divided by ten, and was reported as the mean score for anxiety feelings, with a maximum of 5 . This variable thus measured the intensity of feelings of anxiety. A reliability analysis shows a Cronbach's Alpha of 0.90 for the anxiety scale.

Depressive feelings were measured via a 13-item scale within the SCL-90-R. Respondents were asked to indicate how often they had certain feeling or expressed specific behaviors (worry too much about things, feeling no interest in things, loss of sexual interest or pleasure, thoughts of ending your life, crying easily, feelings of being trapped or caught, blaming yourself for things, feeling lonely, feeling blue, feelings of hopelessness about the future, feelings everything is an effort and feelings of worthlessness). Response categories ranged between 1 (not at all) and 5 (extremely). The scale total was the sum of all item-responses, divided by 13 and was reported as the mean score for depressive feelings, with a maximum of 5 . This variable thus measured the intensity of depressive feelings. A reliability analysis shows a Cronbach's Alpha of 0.92 for the depression scale.

Level of education was measured through the highest obtained educational degree of the respondent and distinguished between (1) no diploma, (2) secondary education degree, and (3) higher education degree. Finally, a categorical help-seeking behavior variable was included, assessing having either visited a general practitioner (GP) and/or a psychologist in the past 12 months. It consisted of four categories: having visited neither (1), having visited only a GP (2), and having visited only a psychologist (3), and having visited both a psychologist and GP (3). Unfortunately, HIS did not offer a consistently measured variable for having visited a psychiatrist or an alternative practitioner.

Control variables - Our analyses were controlled for gender and age. We also controlled for the curvilinear association between age and our outcome variables (see e.g. 46).

\section{Statistical procedures}

In a first step, we present a visualization of time trends for psycholeptics and psychoanaleptics use compared to having AD and DD feelings, which are presented in Figure 1. Figure 2 presents the association between educational level and psycholeptic and psychoanaleptic drugs use throughout the observed period. Descriptives of all included variables are presented in the Appendix Table A1.

In a next step, our hypotheses were tested using multinomial logistic regression analyses. Models 1, 2, and 3 are presented in Table 1 . In model 1 , we analyzed the effect of wave on the psychotropic drugs use outcomes, establishing the effect of time trends, which tested the first hypothesis. Models 2 and 3 , respectively, added the feelings of anxiety and depression scales and interaction terms between feelings of anxiety and depression, and waves. There, we tested our second hypothesis, analyzing the influence of having had feelings of anxiety and depression on psychotropic drugs use. Models 4 and 5 are presented in Table 2. Model 4 assesses the effect of a possible educational gradient on psychotropic drugs use, which tested hypothesis 3 . Model 5 then includes three-way interactions between wave, feelings of anxiety and depression, and educational level. 
Table 1

Multinomial logistic regression results for association between feelings of anxiety and depression and the use of psycholeptics, psychoanaleptics, and bo psycholeptic and psychoanaleptic medication, in reference to use of neither psycholeptics nor psychoanaleptics.

\begin{tabular}{|c|c|c|c|c|c|c|c|c|c|c|c|c|c|c|c|c|c|}
\hline & \multicolumn{6}{|c|}{ Use of psycholeptics } & \multicolumn{6}{|c|}{ Use of psychoanaleptics } & \multicolumn{5}{|c|}{$\begin{array}{l}\text { Use of both psycholeptic and } \\
\text { psychoanaleptics }\end{array}$} \\
\hline & \multicolumn{2}{|c|}{ Model 1} & \multicolumn{2}{|c|}{ Model 2} & \multicolumn{2}{|c|}{ Model 3} & \multicolumn{2}{|c|}{ Model 1} & \multicolumn{2}{|c|}{ Model 2} & \multicolumn{2}{|c|}{ Model 3} & \multicolumn{2}{|c|}{ Model 1} & \multicolumn{2}{|c|}{ Model 2} & \multirow{2}{*}{$\begin{array}{l}\text { Model } 3 \\
\text { OR }\end{array}$} \\
\hline & $O R$ & Sig. & $O R$ & Sig. & $O R$ & Sig. & $O R$ & Sig. & $O R$ & Sig. & $O R$ & Sig. & $O R$ & Sig. & $O R$ & Sig. & \\
\hline Intercept & 0.015 & 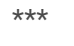 & 0.002 & 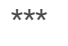 & 0.001 & $\star \star \star *$ & 0.007 & 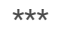 & 0.001 & 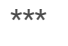 & 0.001 & $\star \star \star$ & 0.000 & 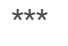 & 0.000 & 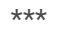 & 0.000 \\
\hline \multicolumn{18}{|l|}{$\begin{array}{l}\text { Waves (ref. } \\
\text { 2008) }\end{array}$} \\
\hline 2004 & 1.064 & & 1.103 & & 1.470 & & 0.942 & & 0.950 & & 1.160 & & 0.984 & & 1.073 & & 0.874 \\
\hline 2013 & 0.711 & $\star \star$ & 0.571 & $\star \star \star$ & 0.942 & & 1.073 & & 0.434 & & 1.579 & & 0.747 & * & 0.561 & 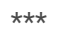 & 0.743 \\
\hline $\begin{array}{l}\text { Feelings of } \\
\text { anxiety }\end{array}$ & & & 2.129 & $\star \star \star$ & 2.070 & $\star \star$ & & & 1.358 & * & 1.227 & & & & 1.958 & 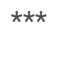 & 2.106 \\
\hline $\begin{array}{l}\text { Feelings of } \\
\text { depression }\end{array}$ & & & 1.668 & $\star \star \star$ & 2.033 & $\star \star \star$ & & & 2.069 & $\star * \star$ & 2.682 & $\star \star \star *$ & & & 2.577 & $\star \star \star *$ & 2.526 \\
\hline \multicolumn{18}{|l|}{$\begin{array}{l}\text { Wave (ref. } \\
2008)^{\star} \text { feelings } \\
\text { of anxiety }\end{array}$} \\
\hline $\begin{array}{l}2004^{\star} \text { feelings } \\
\text { of anxiety }\end{array}$ & & & & & 1.103 & & & & & & 1.145 & & & & & & 0.950 \\
\hline $\begin{array}{l}2013^{\star} \text { feelings } \\
\text { of anxiety }\end{array}$ & & & & & 1.019 & & & & & & 0.122 & & & & & & 0.855 \\
\hline \multicolumn{18}{|c|}{$\begin{array}{l}\text { Wave (ref. } \\
\text { 2008)^feelings of } \\
\text { depression }\end{array}$} \\
\hline $\begin{array}{l}2004) \star \text { feelings } \\
\text { of depression }\end{array}$ & & & & & 0.770 & & & & & & 0.787 & & & & & & 1.135 \\
\hline $\begin{array}{l}2013) \star \text { feelings } \\
\text { of depression }\end{array}$ & & & & & 0.728 & & & & & & 0.605 & & & & & & 0.962 \\
\hline $\begin{array}{l}\text { Gender (ref. } \\
\text { male) }\end{array}$ & 1.479 & $\star \star \star$ & 1.258 & $\star \star$ & 1.257 & * & 1.932 & 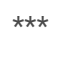 & 1.522 & $\star \star \star$ & 1.519 & $\star \star \star$ & 2.835 & $\star \star \star$ & 2.033 & $\star \star \star$ & 2.028 \\
\hline Age & 1.052 & * & 1.059 & $\star \star$ & 1.060 & * & 1.109 & 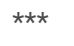 & 1.135 & $\star \star \star ~$ & 1.137 & $\star \star \star$ & 1.201 & $\star \star \star$ & 1.204 & $\star \star \star ~$ & 1.206 \\
\hline $\mathrm{Age}^{2}$ & 1.000 & & 1.000 & & 1.000 & & 0.999 & $\star \star \star *$ & 0.999 & $\star \star \star$ & 0.999 & $\star \star \star ~$ & 0.998 & $\star \star \star$ & 0.999 & $\star \star \star ~$ & 0.999 \\
\hline
\end{tabular}


Table 2

Multinomial logistic regression results for association between feelings of anxiety and depression, education and wave and the use of psycholeptics, psychoanaleptics and both psycholeptics and psychoanaleptics, in reference to use of neither psycholeptics nor psychoanaleptics.

\begin{tabular}{|c|c|c|c|c|c|c|c|c|c|c|c|c|}
\hline & \multicolumn{4}{|c|}{ Use of psycholeptics } & \multicolumn{4}{|c|}{ Use of psychoanaleptics } & \multicolumn{4}{|c|}{$\begin{array}{l}\text { Use of both psycholeptic and } \\
\text { psychoanaleptics }\end{array}$} \\
\hline & \multicolumn{2}{|c|}{ Model 4} & \multicolumn{2}{|c|}{ Model 5} & \multicolumn{2}{|c|}{ Model 4} & \multicolumn{2}{|c|}{ Model 5} & \multicolumn{2}{|c|}{ Model 4} & \multicolumn{2}{|l|}{ Model 5} \\
\hline & $O R$ & Sig. & $O R$ & Sig. & $O R$ & Sig. & $O R$ & Sig. & $O R$ & Sig. & $O R$ & Sig. \\
\hline Intercept & 0.003 & $\star \star \star ~$ & 0.003 & $\star \star \star$ & 0.007 & $\star \star \star$ & 0.001 & $\star \star \star$ & 0.000 & $\star \star \star ~$ & 0.00002 & $\star \star \star ~$ \\
\hline \multicolumn{13}{|l|}{ Waves (ref. 2008) } \\
\hline 2004 & 1.079 & & 1.340 & & 1.001 & & 1.004 & & 1.043 & & 1.595 & \\
\hline 2013 & 0.591 & $\star \star \star$ & 0.406 & & 0.974 & & 1.422 & & 0.567 & $\star \star * *$ & 1.518 & \\
\hline Feelings of anxiety & 2.124 & $\star \star \star ~$ & 1.350 & & 1.372 & * & 0.647 & & 1.918 & $\star \star \star ~$ & 1.314 & \\
\hline Feelings of depression & 1.597 & $\star \star \star ~$ & 2.045 & & 2.037 & $\star \star \star$ & 0.051 & & 2.532 & $\star \star \star ~$ & 2.816 & * \\
\hline \multicolumn{13}{|l|}{ Education (ref. no diploma) } \\
\hline Secondary school diploma & 0.998 & & 0.585 & & 0.946 & & 0.451 & & 1.072 & & 0.910 & \\
\hline Higher education diploma & 0.593 & $\star \star \star ~$ & 0.260 & * & 1.002 & & 0.226 & & 0.714 & & 0.327 & \\
\hline \multicolumn{13}{|l|}{ Wave*feelings of anxiety } \\
\hline $2004 *$ feelings of anxiety & & & 4.327 & ** & & & 1.828 & & & & 1.457 & \\
\hline $2013 *$ feelings of anxiety & & & 1.467 & & & & 1.033 & & & & 1.063 & \\
\hline \multicolumn{13}{|l|}{ Wave (ref. 2008)^feelings of depression } \\
\hline $2004 *$ feelings of depression & & & 0.241 & ** & & & 0.665 & & & & 0.650 & \\
\hline $2013^{\star}$ feelings of depression & & & 0.813 & & & & 0.785 & & & & 0.803 & \\
\hline \multicolumn{13}{|l|}{ Wave (ref. 2008)^ education (ref. no diploma) } \\
\hline $2004 *$ secondary education diploma & & & 0.709 & & & & 0.784 & & & & 0.307 & \\
\hline $2013^{*}$ secondary education diploma & & & 3.932 & & & & 1.324 & & & & 0.563 & \\
\hline 2004*higher education diploma & & & 2.635 & & & & 2.899 & & & & 1.250 & \\
\hline 2013*higher education diploma & & & 1.662 & & & & 1.347 & & & & 0.454 & \\
\hline \multicolumn{13}{|l|}{ Education (ref. no diploma)* feelings of anxiety } \\
\hline Secondary education diploma* feelings of anxiety & & & 2.693 & * & & & 2.828 & & & & 3.067 & \\
\hline Higher education diploma*feelings of anxiety & & & 0.611 & & & & 1.274 & & & & 0.621 & \\
\hline \multicolumn{13}{|l|}{ Education (ref. no diploma)* feelings of depression } \\
\hline Secondary education diploma*feelings of depression & & & 0.614 & & & & 0.701 & & & & 0.496 & \\
\hline Higher education diploma*feelings of depression & & & 2.658 & & & & 1.948 & & & & 3.158 & \\
\hline \multicolumn{13}{|l|}{$\begin{array}{l}\text { Wave (ref. 2008)*education (ref. no diploma)*feelings } \\
\text { of anxiety }\end{array}$} \\
\hline $\begin{array}{l}2004 * \text { secondary education diploma*feelings of } \\
\text { anxiety }\end{array}$ & & & 0.111 & ** & & & 0.540 & & & & 0.379 & \\
\hline $\begin{array}{l}2013^{*} \text { secondary education diploma*feelings of } \\
\text { anxiety }\end{array}$ & & & 0.338 & & & & 0.918 & & & & 0.508 & \\
\hline $2004 *$ higher education diploma*feelings of anxiety & & & 0.339 & & & & 0.799 & & & & 1.298 & \\
\hline $2013 *$ higher education diploma*feelings of anxiety & & & 2.732 & & & & 2.109 & & & & 1.347 & \\
\hline \multicolumn{13}{|l|}{$\begin{array}{l}\text { Wave (ref. 2008)* education (ref. no diploma)*feelings } \\
\text { of depression }\end{array}$} \\
\hline $2004 *$ secondary education diploma*feelings of depressio & & & 8.017 & ** & & & 1.496 & & & & 3.709 & \\
\hline $2013^{*}$ secondary education diploma*feelings of depressio & & & 1.343 & & & & 0.859 & & & & 1.637 & \\
\hline $\begin{array}{l}\text { 2004*higher education diploma*feelings of } \\
\text { depression }\end{array}$ & & & 1.615 & & & & 0.639 & & & & 0.534 & \\
\hline
\end{tabular}

* $p<0.05$ ** $p<0.01$ *** $p<0.001 ; n=7214$. 


\begin{tabular}{|c|c|c|c|c|c|c|c|c|c|c|}
\hline & \multicolumn{4}{|c|}{ Use of psycholeptics } & \multicolumn{2}{|c|}{ Use of psychoanaleptics } & \multicolumn{4}{|c|}{$\begin{array}{l}\text { Use of both psycholeptic and } \\
\text { psychoanaleptics }\end{array}$} \\
\hline $\begin{array}{l}\text { 2013*higher education diploma*feelings of } \\
\text { depression }\end{array}$ & & & 0.294 & & & 0.455 & & & 0.604 & \\
\hline Gender (ref. male) & 1.255 & $\star \star \star *$ & 1.257 & * & 1.508 & $\star \star \star$ & 2.094 & 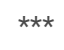 & 2.130 & $\star \star \star *$ \\
\hline Age & 1.055 & * & 1.061 & * & 1.138 & $\star \star \star *$ & 1.213 & $* * *$ & 1.225 & $\star * \star *$ \\
\hline $\mathrm{Age}^{2}$ & 1.000 & & 1.000 & & 0.999 & $\star \star \star \star$ & 0.998 & $\star \star \star *$ & 0.998 & 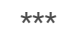 \\
\hline
\end{tabular}

Finally, a number of sensitivity analyses were performed. First, time trends in psycholeptics and psychoanaleptics use for respondents with $A D$ and $D D$ were also estimated, by categorizing respondents as having AD or DD when the scale total was more than 2 on the respective anxiety and depression scales, as is suggested by HIS (47). Second, help-seeking behavior was added to the models, in order to examine whether and how this variable mediates the established associations. Results are presented in the Appendix (Figure A1 and Table A2) and discussed in the text. All analyses were performed with the IBM SPSS Statistics software package (version 27).

\section{Results \\ Descriptives}

As Figure 1 shows, the use of psycholeptic drugs has decreased during the observed period, while the use of psychoanaleptic drugs has increased modestly. Moreover, both feelings of anxiety and depression have been on the rise. Herein, depressive feelings tended to rise more substantially compared to anxiety feelings. Figure A1 additionally shows that, while the likelihood of psycholeptics use decreased over time, psychoanaleptics use increased substantially for persons with AD. In 2013, persons with AD consumed more psychoanaleptics than psycholeptics. The use of a combination of both psycholeptic and psychoanaleptic drugs shows a general downward trend.

Figure 2 shows that persons with a lower level of education tended to be more likely to consume either or both psycholeptic and psychoanaleptic drugs. Therein, persons with no education systematically tended to be the most likely to consume psycholeptic drugs. Moreover, persons with the highest level of education were least likely to consume either type of psychotropic drugs, throughout the observed period. The consumption of a combination of psycholeptics and psychoanaleptics shows a general downward trend in the observed period, though not for persons with no diploma.

\section{Multinomial logistic regression results}

Multinomial regression analysis pointed to a significant decrease in likelihood for psycholeptics (Odds Ration, OR=0,711) or a combination of psycholeptics and psychoanaleptics $(\mathrm{OR}=0,747)$ consumption for 2013 when comparing to the reference year 2008, (Model1, Table 1). Persons were also more likely to consume psycholeptics $(\mathrm{OR}=1,064)$ in 2004 . Adding feelings of anxiety and depression to the analyses (Model2) further widened the gap between waves, for both the psycholeptic as well as the combination outcome. Furthermore, having more anxiety feelings increased the odds (OR=2,129) of consuming psycholeptic drugs compared to having consumed no psychotropic drugs, while this effect was weaker for depressive feelings $(\mathrm{OR}=1,668)$. This effect is reversed for the psychoanaleptic outcome, though with a wider gap between anxiety feelings $(\mathrm{OR}=1,358)$ and depressive feelings $(\mathrm{OR}=2,069)$. Having more depressive feelings increased the odds of taking a combination of both psycholeptic and psychoanaleptic drugs, compared to having more anxiety feelings. Model 3 added interaction terms between wave and anxiety feelings and wave and depressive feelings. Though, none of the interaction terms were significant. Having had a higher education (Model 4) did lead to a decrease in odds for consuming psycholeptic drugs (OR=0,593). This effect was reversed for psychoanaleptic drugs use, though it was not significant. Model 5 shows that having more anxiety feelings in 2004, led to a significant increase in the odds of psycholeptic use $(\mathrm{OR}=4,327)$. Having more depressive feelings in 2004 , however, led to a significant decrease in the odds (OR=0,241). Moreover, persons with a secondary level diploma and more anxiety feelings had greater odds $(\mathrm{OR}=2,693)$ to consume psycholeptic drugs as well. The odds increased significantly for persons having more depressive feelings and a secondary diploma in $2004(\mathrm{OR}=8,017)$, compared to having anxiety feelings $(\mathrm{OR}=0,111)$.

Lastly, an additional sensitivity analysis (See Appendix Table A2) revealed that, when compared to model 4, the effect of having more feelings of anxiety and depression slightly decreased when compared to the help-seeking reference category, which is having visited neither GP nor psychologist in the past year, suggesting a mediating effect. The effect of having visited both a GP and psychologist increased the odds of taking psycholeptic drugs (OR=3,417), while having visited only a psychologist had a similar effect $(\mathrm{OR}=3,323)$. However, having visited only a GP had no significant effect on whether respondents used psycholeptics, compared to having used neither psycholeptics or psychoanaleptics. For psychoanaleptic use, effects were more outspoken. Having visited only a psychologist had the biggest effect, increasing odds 16 -fold, while having visited both a psychologist and GP also increased odds tenfold. An important caveat, however, is that the sample size for having visited only a psychologist is rather small $(n=83)$ when compared to the other categories. Having visited only a GP had a significant effect (OR=2,609), too, suggesting GP's were more likely to prescribe psychoanaleptics than psycholeptics. For the combination outcome, having visited both GP and psychologist had a significant effect, increasing the odds by a factor of 8,6.

\section{Discussion}

Distinguishable patterns of psychotropic drugs use for mitigating feelings of anxiety and depression have been described throughout the observed period. While both feelings of anxiety and depression were on the rise in Belgium, psycholeptics became more obscured, while psychoanaleptics have been booming. 
We can therefore confirm our first hypothesis. This trend was also confirmed by other researchers in other contexts, who noted a shift to psychoanaleptic drugs (specifically antidepressants) occurred in the late 2000 s $(26,48)$.

The consumption of psycholeptics and psychoanaleptics was influenced not only by scientific developments, but also by how society perceives these types of treatments (49). This could be ascribed to three reasons. First, psycholeptic drugs (such as benzodiazepines) are notoriously addictive (50). It is argued that the prolonged use of this type of medication ultimately leads to a dependency, fueled by either long-term, ill-managed treatment by, e.g., general practitioners, which could result in addiction or the use of illicit drugs $(51,52)$. This rhetoric is often bloated by the media (see e.g. 53), further fueling fears and doubt surrounding this treatment method. Second, the use of psycholeptic drugs is associated with substantial health problems, such as cognitive decline, especially among the elderly (54), and withdrawal syndrome (50). Therefore, short-term psycholeptic use is most often advised. Third, developments in psychoanaleptic drugs treatment systematically showed promising results in the last thirty years (55). However, while the first antidepressants, for instance, were received with great enthusiasm, their side-effects were often overlooked and minimized when compared to psycholeptics (25).

Others (e.g. 25, 26, 56) argue that the use of benzodiazepines (and other psycholeptic drugs) should be reassessed, claiming its use could lead to benefits that outweigh possibilities of addiction and other health problems. The decrease in psycholeptic drugs use and its prescribing is, at least partially, the result of (societal) biases towards it. In addition, the pharmaceutical industry has increasingly favored, for instance, antidepressants over benzodiazepines in the last two decades (13). This has led to rigorous new treatment protocols and even legislation to help restrict psycholeptic drugs use. Shifts in treatment are also caused by the systematic reframing of both disorders $(4,7,24)$. For instance, the reframing of DD, particularly by the APA's DSM-III, changed the perception on mental disorders drastically (9). DD became an umbrella term for a large number of (mood) disorders, causing prevalence rates to increase substantially (4). All the while, AD was being subdivided into multiple new disorders (20). In addition, the APA argued that treatment with psychoanaleptics was more suited to these new (anxiety) diagnoses $(12,25)$. This study shows that it could have rather been the other way around.

Our research additionally established the existence of a social gradient within the consumption of psycholeptic and psychoanaleptic drugs, confirming our third hypothesis. Higher educated persons consumed less of either (or both) psycholeptic and psychoanaleptic drugs throughout all of the observed period. This could firstly be explained by the already existing social gradient in the distribution of mental illnesses, with persons having enjoyed less education being more susceptible to them in the first place $(57,58)$. Nielsen, Hansen $(57)$ argue that medication consumption is congruent with this distribution, resulting in more consumption with those that are lower educated compared to those who are higher educated. Secondly, persons with less education often have more difficulty navigating health care systems, leading them to accept treatment methods that are most easily available, usually via ambulatory care (15, 59). In the United States, for example, acute anxiety attacks are often relieved with a one-time psycholeptics prescription (60). Though, this practice is becoming less common for persons with lower SES due to (sometimes unfounded) suspicions of substance abuse (52). Thirdly, the prescribing behavior of clinicians and subsequent treatment of mental disorders varies between patients with different educational backgrounds (61). This could be due to stigma revolving around psychiatric treatment $(49,58)$, which was already discussed specifically in the case of psycholeptics and benzodiazepines, but is also true for most medication-based treatments $(25,37,61)$.

Moreover, the use of psychoanaleptics is most prevalent in persons with the highest educational level. Newer types of treatment, such as psychoanaleptics, are often more readily available for persons with a higher educational level (e.g. 62), while they are deemed less hazardous and thus less stigmatizing (25). Our results suggest that the shift to psychoanaleptic drugs in persons with the highest education already happened before the observed period, but that this shift is now occurring for persons with secondary education, describing a diffusion of psychotropic innovations. Persons with higher education, furthermore, increasingly opt for alternative types of treatment to prevent stigma, while taking on an active patient role, while persons with lower education generally still take on a more passive patient role (63).

Finally, the literature suggests there are recent trends of demedicalization in the treatment (or prevention) of mental illness (16, 43). We performed a sensitivity analysis to investigate differences in the medication use outcome when controlled for different forms of help-seeking behavior. Therein, having visited only a GP returned the lowest likelihood of psycholeptic or psychoanaleptic drugs consumption, suggesting primary care prescriptions for psycholeptics or psychoanaleptics are less common than when patients also visited a psychologist. This could indicate that medicinal treatments are increasingly combined with talking therapy, as is most often advised nowadays $(12,55,64)$. However, since we could not include a variable for psychiatry or alternative medicine, evidence to support these trends is lacking in comprehensiveness.

While interpreting the results, some limitations of this study are worth noting. First, the SCL-90-R measurement could be partially mediated by medication use, leading to response-biases. Second, the observed period is rather limited in duration. Third, this study did not take into account the high comorbidity between $A D$ and DD. Finally, our ideal-typical distinction between psycholeptic and psychoanaleptic drugs excludes other medication types or combinations of psychotropic drugs that are often used to treat both disorders.

\section{Conclusions}

In conclusion, this study provides evidence for a shift in the medicalization of both feelings of anxiety and depression, and that the medicalization of these feelings was dissimilar, but indeed converging towards another. Using the ideal-typical distinction of psycholeptics and psychoanaleptics allowed us to test the medicalization framework as a means to unambiguously assess differences between both disorders. Finally, we established a social gradient that partially mediated these shifts. This, by itself, means that treatment for feelings of anxiety and depression was perceived differently for different persons (in this case depending on educational level).

\section{List Of Abbreviations}




\begin{tabular}{|ll|}
\hline AD & Anxiety Disorder \\
\hline DD & Depressive Disorder \\
SSRI & Serotonine Reuptake Inhibitor \\
\hline HIS & Health Interview Survey \\
\hline APA & American Psychological Association \\
\hline DSM & Diagnostic and Statistical Manual of Mental Disorders \\
\hline MDD & Major Depressive Disorder \\
\hline NIHDI & National Institute for Health and Disability Insurance \\
\hline BelPEP & Belgian Psychotropics Experts Platform \\
\hline ATC & Anatomical Therapeutic Classification \\
\hline SCL-90-R & Symptom Checklist Revised \\
\hline GP & General Practitioner \\
\hline OR & Odds Ratio \\
\hline
\end{tabular}

\section{Declarations}

\section{Ethics approval and consent to participate}

This study has been approved by the appropriate ethics committee (EASHW at the University of Antwerp) and has therefore been performed in accordance with the ethical standards laid down in the 1694 Declaration of Helsinki and its later amendments. All participants gave informed consent to participate in this study. All personal details were omitted to guarantee complete anonymity.

\section{Consent for publication}

All relevant parties read and approved the manuscript for publication.

\section{Availability of data and material}

Data was formally obtained via BHIS, the Belgian Health Interview Survey, as collected by Sciensano. Data is only accessible through the formal channels, and will thus not be published alongside this manuscript.

\section{Competing interests}

Not applicable.

\section{Funding}

Not applicable.

\section{Authors' contributions}

KVL contributed to the conceptualization, methodology, formal analysis, and writing the original draft of this manuscript. SVDV contributed to conceptualization, review and editing, and supervision. All authors read and approved the final manuscript.

\section{Acknowledgements}

This manuscript was originally drafted to obtain the degree of Master in Sociology by Kilian Van Looy (academic year 2020-2021), under mentorship of prof. Sarah Van de Velde. It then was reformatted to better meet the requirements of an academic publication.

\section{References}

1. Kessler RC. Overview of Descriptive Epidemiology of Mental Disorders. In: Aneshensel CS, Phelan JC, Bierman A, editors. Handbook of the Sociology of Mental Health. Dordrecht: Springer Netherlands; 2013. p. 169-82.

2. Craske MG, Stein MB. Anxiety. The Lancet. 2016;388(10063):3048-59. 
3. Kessler RC, Petukhova M, Sampson NA, Zaslavsky AM, Wittchen H-U. Twelve-month and lifetime prevalence and lifetime morbid risk of anxiety and mood disorders in the United States. International journal of methods in psychiatric research. 2012;21(3):169-84.

4. Horwitz AV. How an age of anxiety became an age of depression. The Milbank quarterly. 2010;88(1):112-38.

5. Mwinyi J, Pisanu C, Castelao E, Stringhini S, Preisig M, Schiöth HB. Anxiety Disorders are Associated with Low Socioeconomic Status in Women but Not in Men. Women's Health Issues. 2017;27(3):302-7.

6. Hirschfeld RM. The Comorbidity of Major Depression and Anxiety Disorders: Recognition and Management in Primary Care. Prim Care Companion J Clin Psychiatry. 2001;3(6):244-54.

7. Conrad P. The Shifting Engines of Medicalization. Journal of Health and Social Behavior. 2005;46(1):3-14.

8. Conrad P, Schneider JW. Deviance and Medicalization: From Badness to Sickness: Temple University Press; 1992.

9. Horwitz AV. Transforming Normality into Pathology: The DSM and the Outcomes of Stressful Social Arrangements. Journal of Health and Social Behavior. 2007;48(3):211-22.

10. Conrad P, Barker KK. The Social Construction of Illness: Key Insights and Policy Implications. Journal of Health and Social Behavior. 2010;51(1_suppl):S67-S79.

11. Schnittker J. Public Beliefs About Mental IIIness. In: Aneshensel CS, Phelan JC, Bierman A, editors. Handbook of the Sociology of Mental Health. Dordrecht: Springer Netherlands; 2013. p. 75-93.

12. Bandelow B, Michaelis S, Wedekind D. Treatment of anxiety disorders. Dialogues in clinical neuroscience. 2017;19(2):93-107.

13. Spence D. Bad Medicine: The rise and rise of antidepressants. The British journal of general practice : the journal of the Royal College of General Practitioners. 2016;66(652):573-.

14. Link BG, Phelan J. Social Conditions As Fundamental Causes of Disease. Journal of Health and Social Behavior. 1995:80-94.

15. Pampel FC, Krueger PM, Denney JT. Socioeconomic Disparities in Health Behaviors. Annual review of sociology. 2010;36:349-70.

16. Clarke AE, Shim JK, Mamo L, Fosket JR, Fishman JR. Biomedicalization: Technoscientific Transformations of Health, Illness, and U.S. Biomedicine. American Sociological Review. 2003;68(2):161-94.

17. Horwitz AV, Wakefield J. All We Have to Fear: Psychiatry's Transformation of Natural Anxieties into Mental Disorders: Oxford University Press; 2012.

18. Horwitz AV, Wakefield J. The loss of sadness: How psychiatry transformed normal sorrow into depressive disorder. New York, NY, US: Oxford University Press; 2007. xv, 287-xv, p.

19. Bruce ML, Raue PJ. Mental Illness as Psychiatric Disorder. In: Aneshensel CS, Phelan JC, Bierman A, editors. Handbook of the Sociology of Mental Health. Dordrecht: Springer Netherlands; 2013. p. 41-59.

20. Starkstein S. A Conceptual and Therapeutic Analysis of Fear. London: Palgrave Macmillan; 2018.

21. Deacon BJ. The biomedical model of mental disorder: A critical analysis of its validity, utility, and effects on psychotherapy research. Clinical Psychology Review. 2013;33(7):846-61.

22. Scott S. The medicalisation of shyness: from social misfits to social fitness. Sociol Health Illn. 2006;28(2):133-53.

23. Pies RW. The Bereavement Exclusion and DSM-5: An Update and Commentary. Innovations in clinical neuroscience. 2014;11(7-8):19-22.

24. Horwitz AV. Creating an Age of Depression: The Social Construction and Consequences of the Major Depression Diagnosis. Society and Mental Health. 2011;1(1):41-54.

25. Balon R, Starcevic V, Silberman E, Cosci F, Dubovsky S, Fava GA, et al. The rise and fall and rise of benzodiazepines: a return of the stigmatized and repressed. Brazilian Journal of Psychiatry. 2020;42:243-4.

26. Offidani E, Guidi J, Tomba E, Fava GA. Efficacy and tolerability of benzodiazepines versus antidepressants in anxiety disorders: a systematic review and meta-analysis. Psychother Psychosom. 2013;82(6):355-62.

27. Ehrenberg A. The weariness of the self: Diagnosing the history of depression in the contemporary age. Montreal: McGill-Queen's University Press; 2010.

28. Declercq T, Habraken H, Van Den Ameele H, Callens J, De Lepeleire J, Cloetens H. Depressie Bij Volwassenen: Herziening in opdracht van de commissie richtlijnen. Antwerpen: Domus Medica VZW; 2016.

29. Gisle L, Drieskens S, Demarest S, Van der Heyden J. Geestelijke gezondheid: gezondheidsenquête 2018. Brussel: Sciensano, Sciensano; 2018. Report No.: D/2020/14.440/4 Contract No.: D/2020/14.440/4.

30. Kurko T, Saastamoinen LK, Tuulio-Henriksson A, Taiminen T, Tiihonen J, Airaksinen M, et al. Trends in the long-term use of benzodiazepine anxiolytics and hypnotics: A national register study for 2006 to 2014. Pharmacoepidemiol Drug Saf. 2018;27(6):674-82.

31. de Looper M, Lafortune G. Measuring Disparities in Health Status and in Access and Use of Health Care in OECD Countries. 2009.

32. De Cock J. Belgische verzekering voor geneeskundige verzorging en uitkeringen: Mijlpalen van het verleden, bakens voor de toekomst. In: RIZIV, editor. 2014.

33. Davies K, Stremikis K, Squires D, Schoen C. Mirror, Mirror on the Wall: How the Performance of the U.S. Health Care System Compares Internationally. The Commonwealth Fund; 2014.

34. Field MG. Comparative Health Systems and the Convergence Hypothesis: The Dialectics of Universalism and Particularism. In: Powell FD, Wessen AF, editors. Health Care Systems in Transition: An International Perspective. California: Thousand Oaks; 1999. p. 35-44.

35. BelPEP. Globale visienota en actieplan van de 3 werkgroepen. 2015.

36. Bell AV. The margins of medicalization: Diversity and context through the case of infertility. Social Science \& Medicine. 2016;156:39-46.

Page $10 / 13$ 
37. Sleath B, Tina Shih Y-C. Sociological influences on antidepressant prescribing. Social Science \& Medicine. 2003;56(6):1335-44.

38. Muntaner C, Ng E, Vanroelen C, Christ S, Eaton WW. Social Stratification, Social Closure, and Social Class as Determinants of Mental Health Disparities. In: Aneshensel CS, Phelan JC, Bierman A, editors. Handbook of the Sociology of Mental Health. Dordrecht: Springer Netherlands; 2013. p. 205-27.

39. McLeod JD. Social Stratification and Inequality. In: Aneshensel CS, Phelan JC, Bierman A, editors. Handbook of the Sociology of Mental Health. Dordrecht: Springer Netherlands; 2013. p. 229-53.

40. Bjelland I, Krokstad S, Mykletun A, Dahl A, Tell G, Tambs K. Does higher education protect against anxiety and depression? The HUNT study. Social science \& medicine (1982). 2008;66:1334-45.

41. Dudal P, Bracke P. Absolute and relative educational inequalities in depression in Europe. International Journal of Public Health. $2016 ; 61$.

42. Demyttenaere K, Bonnewyn A, Bruffaerts R, De Girolamo G, Gasquet I, Kovess V, et al. Clinical factors influencing the prescription of antidepressants and benzodiazepines: results from the European study of the epidemiology of mental disorders (ESEMeD). J Affect Disord. 2008;110(1-2):84-93.

43. Hofmann SG, Sawyer AT, Witt AA, Oh D. The effect of mindfulness-based therapy on anxiety and depression: A meta-analytic review. Journal of consulting and clinical psychology. 2010;78(2):169-83.

44. World Health Organization. Structure and principles 2018 [Available from: https://www.whocc.no/atc/structure_and_principles/.

45. Derogatis LR. SCL-90-R : symptom checklist-90-R : administration, scoring \& procedures manual. Minneapolis: National Computer Systems, Inc.; 1994.

46. Mirowsky J, Ross CE. Age and Depression. Journal of Health and Social Behavior. 1992;33(3):187-205.

47. Gisle L. Geestelijke gezondheid. In: Van der Heyden J, Charafeddine R, editors. Gezondheidsenquête 2013. Brussel: WIV-ISP; 2014.

48. John U, Sebastian E, Völzke H, Grabe H, Freyberger H, Alte D. Estimation of psycholeptic and psychoanaleptic medicine use in an adult general population sample using the Anatomical Therapeutic Chemical classification. International journal of methods in psychiatric research. 2008;17:220-31.

49. Angermeyer MC, Breier P, Dietrich S, Kenzine D, Matschinger H. Public attitudes toward psychiatric treatment. Social Psychiatry and Psychiatric Epidemiology. 2005;40(11):855-64.

50. Brett J, Murnion B. Management of benzodiazepine misuse and dependence. Australian prescriber. 2015;38(5):152-5.

51. Ashton H. The diagnosis and management of benzodiazepine dependence. Curr Opin Psychiatry. 2005;18(3):249-55.

52. Schmitz A. Benzodiazepine use, misuse, and abuse: A review. The mental health clinician. 2016;6(3):120-6.

53. Garrison A. Antianxiety drugs - often more deadly than opioids - are fueling the next drug crisis in US 2018 [Available from: https://www.cnbc.com/2018/08/02/antianxiety-drugs-fuel-the-next-deadly-drug-crisis-in-us.html.

54. Paterniti S, Dufouil C, Alpérovitch A. Long-Term Benzodiazepine Use and Cognitive Decline in the Elderly: The Epidemiology of Vascular Aging Study. Journal of Clinical Psychopharmacology. 2002;22(3).

55. Cuijpers P, Stringaris A, Wolpert M. Treatment outcomes for depression: challenges and opportunities. The Lancet Psychiatry. 2020;7(11):925-7.

56. Silberman E, Balon R, Starcevic V, Shader R, Cosci F, Fava GA, et al. Benzodiazepines: it's time to return to the evidence. The British Journal of Psychiatry. 2021;218(3):125-7.

57. Nielsen MW, Hansen EH, Rasmussen NK. Patterns of psychotropic medicine use and related diseases across educational groups: national cross-sectional survey. Eur J Clin Pharmacol. 2004;60(3):199-204.

58. Seifert J, Führmann F, Reinhard MA, Engel RR, Bernegger X, Bleich S, et al. Sex differences in pharmacological treatment of major depressive disorder: results from the AMSP pharmacovigilance program from 2001 to 2017. Journal of Neural Transmission. 2021.

59. Kangovi S, Barg FK, Carter T, Long JA, Shannon R, Grande D. Understanding Why Patients Of Low Socioeconomic Status Prefer Hospitals Over Ambulatory Care. Health Affairs. 2013;32(7):1196-203.

60. Agarwal SD, Landon BE. Patterns in Outpatient Benzodiazepine Prescribing in the United States. JAMA Netw Open. 2019;2(1):e187399.

61. Dorner TE, Mittendorfer-Rutz E. Socioeconomic inequalities in treatment of individuals with common mental disorders regarding subsequent development of mental illness. Soc Psychiatry Psychiatr Epidemiol. 2017;52(8):1015-22.

62. Drake R, Skinner J, Goldman HH. What explains the diffusion of treatments for mental illness? The American journal of psychiatry. 2008;165(11):1385-92.

63. Smith SG, Pandit A, Rush SR, Wolf MS, Simon CJ. The Role of Patient Activation in Preferences for Shared Decision Making: Results From a National Survey of U.S. Adults. J Health Commun. 2016;21(1):67-75.

64. Bleakley S, Davies SJC. The pharmacological management of anxiety disorders. Progress in Neurology and Psychiatry. 2014;18(6):27-32.

\section{Figures}




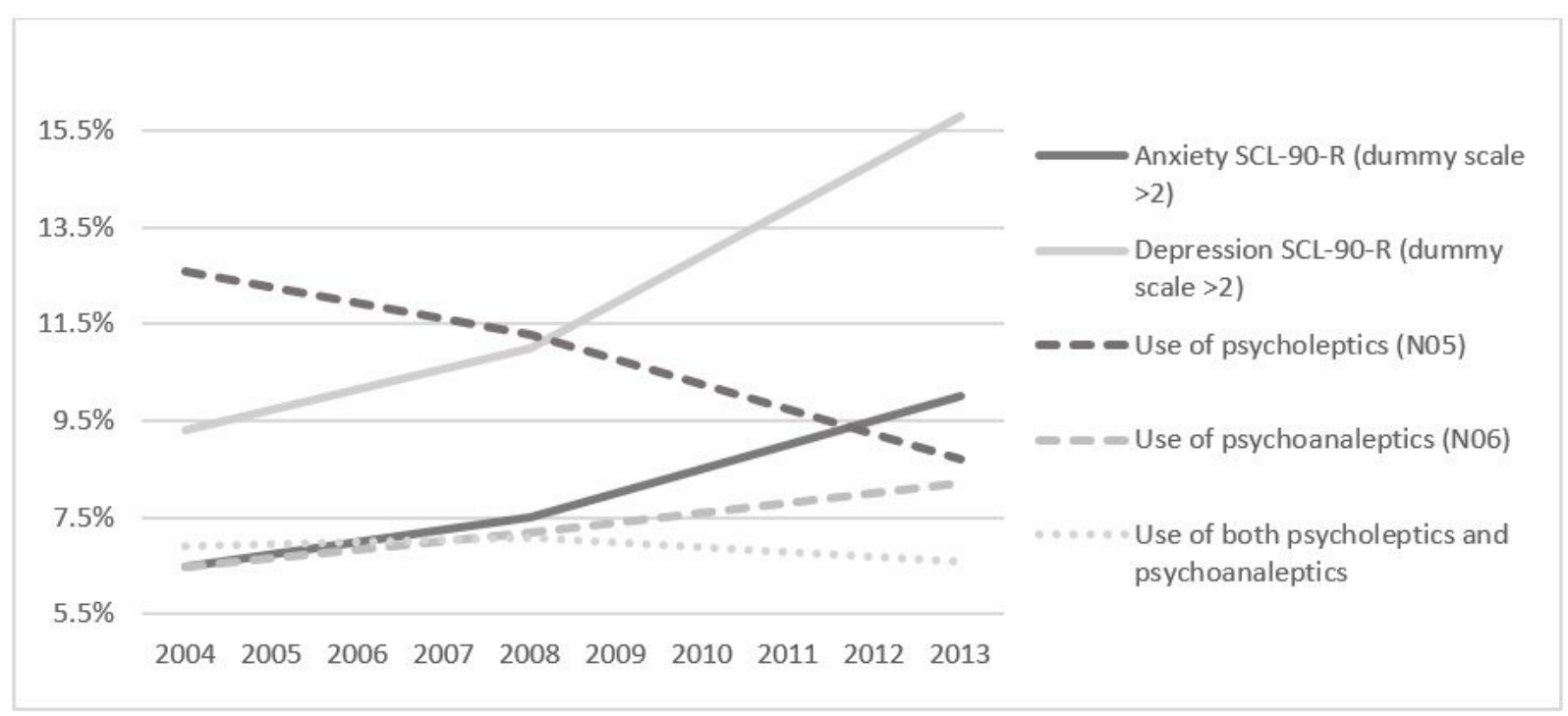

\section{Figure 1}

Trends in psycholeptic and/or psychoanaleptic drugs by feelings of anxiety and depression
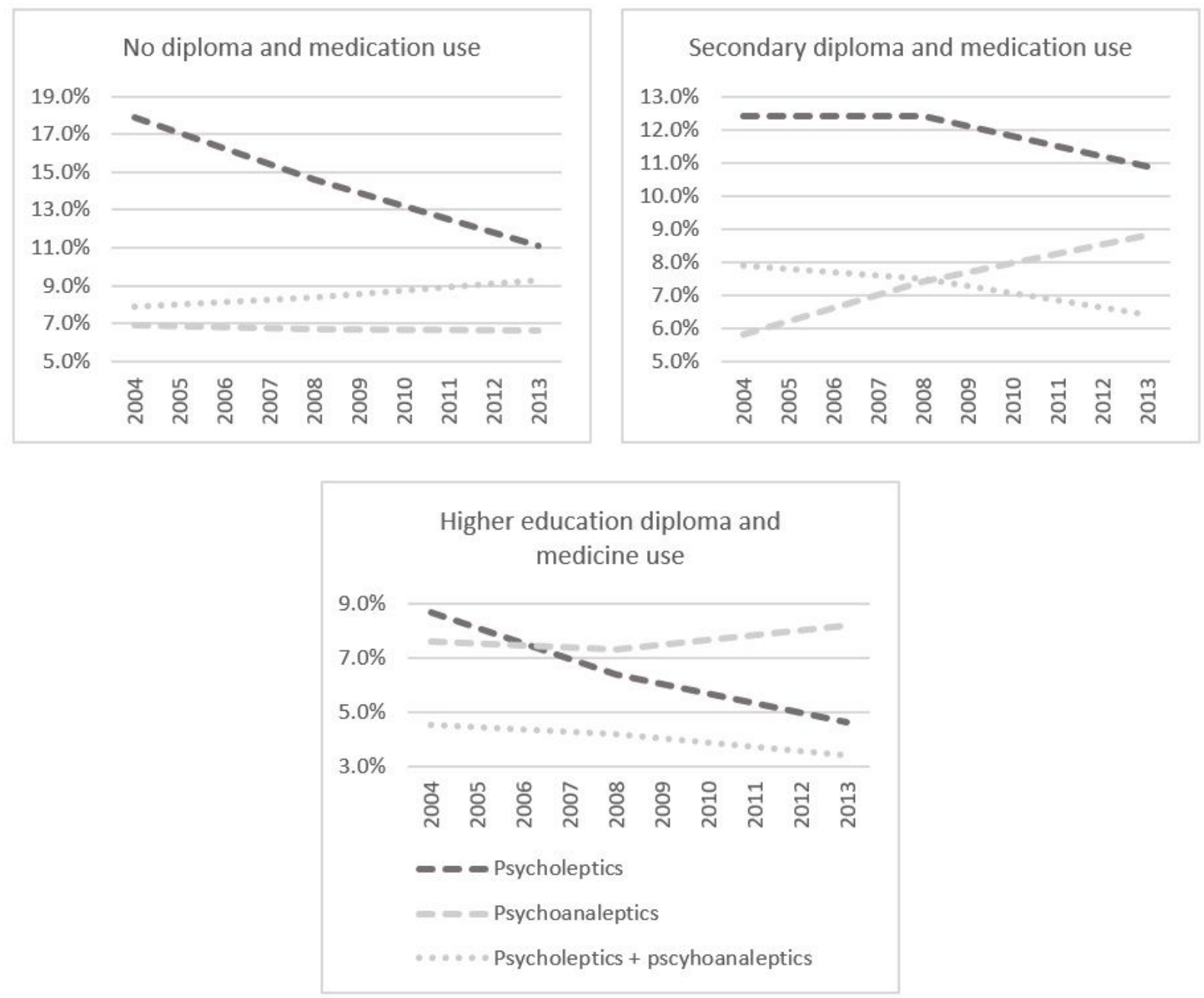

\section{Figure 2}

Trends in psycholeptic and/or psychoanaleptic drugs by educational level.

\section{Supplementary Files}


This is a list of supplementary files associated with this preprint. Click to download.

- APHadditionalfile1.docx

Page 13/13 